\title{
Dynamic analysis of basic tower structure of offshore wind turbine
}

\author{
Dingcheng $\mathrm{Ma}^{1, \mathrm{a}}$ \\ ${ }^{1}$ School of North China Electric Power University, HeBei 071000, China
}

Keywords: Offshore wind turbine, Single pile foundation structure, kinetic analysis

\begin{abstract}
As a clean and renewable energy, the offshore wind energy has profound significance for the improvement of energy structure and protection of ecological environment. Now the design technology of the tower and basic structure of offshore wind turbine in China is immature, and the experience of analyzing the structure of offshore wind turbine under the combined action of all kinds of complex ocean environment loads is poor. So it is necessary to study the dynamic response of offshore wind turbine structure under the offshore environment, and is also valuable to the development of offshore wind power generation.
\end{abstract}

\section{Introduction}

The load of the wind rotor blade of wind turbine operating in wild is complicated, and the loading calculation and strength analysis is vital for the design of wind turbine. The wind rotor blade is the core part of the wind turbine. Understanding its dynamic characteristics is significant for the design of wind rotor blade of wind turbine and wind turbine control.

\section{Dynamic analysis}

\subsection{Environmental load analysis}

The loads of tower structure of wind turbine are very complicated, and can be divided into three categories: permanent loads, variable loads, and accidental loads. The most important loads of tower structure of wind turbine are the wind loads. Besides, the influences of the earthquake action in high seismic intensity area on the tower structure also can't be ignored.

In general, the wind load is evaluated as mean and fluctuating components. The mean wind is the equivalent of static effect, while the fluctuating wind usually cause the vibration of structure. There are two methods to study the dynamic response of tower structure under the influence of wind loads except for experiments: frequency domain method and time domain method. For the tower structure of wind turbine, the effects of wind loads are bigger than the effects of earthquake. But when the wind farm is situated in the high seismic intensity region, the effects of earthquake should be considered to ensure the safety of tower structure.

Now, the seismic checking computation method mainly includes the equivalent base shear method, mode-superposition response spectrum method, and time history analysis method. Compared with the observed actual earthquake, the error of structural seismic response calculated by response spectrum method is smaller and smaller with the improvement of strong motion observation technique and calculation method. So the mode superposition response spectrum method is widely used for the seismic calculation.

2.2 Dynamic characteristics calculation of tower structure

The factors which can cause the vibration of tower structure mainly include: random wind loads, shear speed, impeller eccentricity, start and stop, seismic effects, tower shadow effects, and other emergent loads ${ }^{[1]}$.

During the calculation of dynamic characteristics of tower structure, the engine room and impeller are usually simplified into lumped mass which acts on the top of tower structure. Considering the influences of the inertia moment of the engine room and impeller, the Rayleigh method and matrix analytical method are usually used to calculate the dynamic characteristics of tower structure. For large turbine, the blade stiffness has great influences on the dynamic characteristics of tower structure, and the modal synthesis method can be choose $\mathrm{e}^{[2-4]}$. 
2.3 Interaction mechanics model of offshore wind turbine structure and soil

The interaction mechanics model of structure and soil is a cross discipline developed by structural dynamics and soil dynamics. Similar to offshore platform structure system, there are many factors which can influence the ultimate bearing capacity, such as the interaction mechanic of stake and soil. In general, three methods can be used to solve the problem of interaction mechanics of stake and soil. The first one is considering the soil as the linear elastic continuous medium, which can reflect the geometrical damping of soil and soil resonance. The second method is describing the stake and soil by finite element, which can describe the change of characteristics of stake and soil. The third method is modelling the system of stake and soil by a group of separated lumped mass, spring and damping. The third method can reflect the nonlinear variation of depth and soil which depends on the local stiffness and geometrical damping ${ }^{[5]}$.

2.3.1Interaction mechanics of stake and soil

Under the influence of random dynamic loads, the description of the interaction mechanics of stake and soil can choose the following assumption:

Firstly divided the pile foundation into some subparagraph, and the quality of

each subparagraph concentrates on its centre.

Assume the soil base play a role of nonlinear spring, and retroaction on each centre of the pile foundation.

The end condition of pile foundation can be completely free translation and turn, or free translation but without turn.

2.3.2 Interaction mechanics model of stake and soil

We analyzed the flow of seawater around the tower based on the interaction mechanics model of stake and soil and the assumption of interaction mechanics of stake and soil. According to the finite element analysis method, we finished the design of the structure of single pile foundation of offshore wind turbine, shape of soil around pile, thickness of bottom soil by ICEM model of ANSYS $^{[6]}$.

Parameters:

The main body of single pile foundation structure of offshore wind turbine is cylindrical tube, and the radius is $4 \mathrm{~m}$.

The soil shape around the stake brings into correspondence with the stake and is cylindrical. Assume the edge of the soil around the stake is the same with the 10 times of the stake radius of single stake basic structure of offshore wind turbine $(40 \mathrm{~m})$.

The choose of the thickness of bottom soil: to reduce the influence of the boundary condition on the analysis results, 5 times of the stake radius of single stake basic structure of offshore wind turbine is chosen to represent the thickness of bottom soil in contact with it(20m).

Model building: modelling by the ICEM of ANSYS
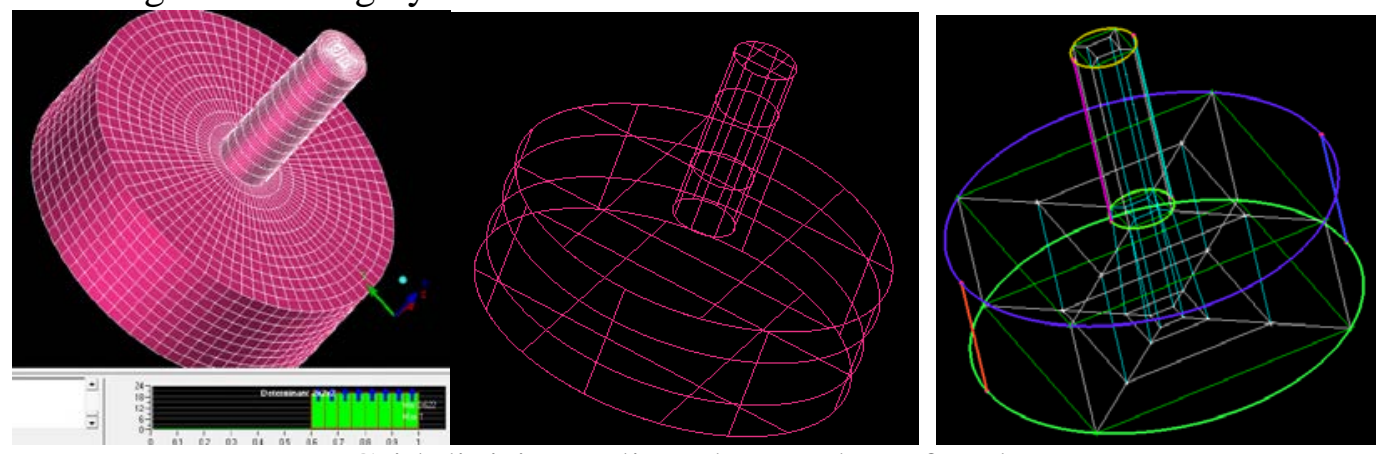

Grid division, adjust the number of nodes

From the integrity grid analysis in above figures, it can be seen that the grid quality of this model is good.

\section{Modeling results}

Whether combined with inner pipes of any pile diameter, the maximum displacement value and 
maximum stress value of the casing concrete pile with the pile diameter of $3.5 \mathrm{~m}$ are all smaller than the circular pipe steel pile with the pile diameter of $4 \mathrm{~m}$ and wall thickness of $50 \mathrm{~mm}$. It means that when we choose the casing concrete pile with the pile diameter of $3.5 \mathrm{~m}$, any combination can meet the safety requirements. Considering the economy, we suggest choosing the casing concrete pile with the wall thickness of $50 \mathrm{~mm}$ and the inner pipe of $1.0 \mathrm{~m}$ to be the basic structure of single pile of offshore wind turbine.

Whether combined with inner pipes of any pile diameter and wall thickness of out pipe except the combination which the pile diameter is $4 \mathrm{~m}$ and the wall thickness of tubular pipe steel pile is $50 \mathrm{~mm}$, the maximum stress value of the casing concrete pile with the pile diameter of $3.0 \mathrm{~m}$ are all smaller than the circular pipe steel pile with the pile diameter of $4 \mathrm{~m}$ and wall thickness of 50mm. But considering the safety, when we choose the casing concrete pile with the out pile diameter of $3.0 \mathrm{~m}$ as the basic structure of single pile of offshore wind turbine, it is suggested to control its maximum displacement value to be smaller than the corresponding value of circular pipe steel pile with the pile diameter of $4 \mathrm{~m}$ and the wall thickness of $50 \mathrm{~mm}$.It means that when we choose the casing concrete pile with the pile diameter of $3.5 \mathrm{~m}$, any combination can meet the safety requirements. Considering the economy and safety, when we choose the casing concrete piles combined with outer pipes with the pile diameter of $3.0 \mathrm{~m}$ as the basic structure of single pile of offshore wind turbine, we suggest choosing the casing concrete pile with the wall thickness of $50 \mathrm{~mm}$ and the inner pipe of $1.5 \mathrm{~m}$.

Whether combined with any pile, the maximum displacement value and maximum stress value of the casing concrete pile with the outer pile diameter of $2.5 \mathrm{~m}$ are all larger than the circular pipe steel pile with the pile diameter of $4 \mathrm{~m}$ and wall thickness of $50 \mathrm{~mm}$, which can't meet the safety requirements. So we suggest not choosing it as the basic structure of single pile of offshore wind turbine.

\section{Summary}

In this paper, we have finished the choosing and design of the structure, soil shapes around the pile and bottom soil thickness of the foundation of the single pile of offshore wind turbine, and gotten its grid distribution combined with the simplified data model. Considering the safety, economy and the current piling technology, two improved schemes have been finished and the casing concrete pile with the outer pipe diameter of $3.0 \mathrm{~m}$, wall thickness of $50 \mathrm{~mm}$ and inner pipe diameter of 1.5 is suggest to be the basic structure of single pile of offshore wind turbine.

\section{Reference}

[1]LiBL , SongXG, HeDX , AnYH . Structuredynamicanaly-sisofwindturbine . Beijing : Beijingaerospaceuniversitypress, 1999: 134 257.

[2]Xin Weiping,The Dynamic Response Analysis of the Rotating Blade of Horizontal Axis Wind Tu rbine.Wind Engineering. Master's Degree Thesis of Shantou University. 2002.

[3]Jian Kai-lin, Ying Xue-gang. Computation of Natural Frequencies of a Rotating Beam. College o f Resources and Environmental Science, Chongqing University, 2001.24(6)36-39.

[4]Mark Lillico,Richard Butler,Finite Element and Dynamic Stiffness Methods Compared for Moda l Analysis of Composite Wings.AIAA Journal, 1998,36(11):214 - 215

[5]He Yansong, Wang Jianfei, Zhao Huaiyu, etc. Research of load calculation and load combination for wind turbine generetor system of beach-shallow sea. Sinosteel Engineering. 2012, 42(S2): 412-4 18.

[6]Li Hong-tao, Li Lin-bin. Research on Desigh Analysis for Support Structure of Offshore Wind T urbine. Offshore Engineering. 2011, 29(4):75 - 81. 